\title{
Absences from work among healthcare workers: are they related to influenza shot adherence?
}

Francesca Antinolfi ${ }^{*}$ D, Claudio Battistella ${ }^{1,2}$, Laura Brunelli $i^{1,3,4}$, Francesca Malacarne ${ }^{1}$, Francesco Giuseppe Bucci ${ }^{1}$, Daniele Celotto ${ }^{1,5}$, Roberto Cocconi ${ }^{3,4}$ and Silvio Brusaferro ${ }^{1}$

\begin{abstract}
Background: The coverage for influenza vaccination among healthcare workers (HCWs) is inadequate in many countries despite strong recommendations; is there evidence that influenza vaccination is effective in preventing absenteeism? Aim of the study is to evaluate the influenza vaccination coverage and its effects on absences from work among HCWs of an Italian academic healthcare trust during the 2017-2018 influenza season.

Methods: We performed a retrospective study to identify predictive characteristics for vaccination, and a retrospective cohort study to establish the effect of vaccination on absences among the vaccinated and non-vaccinated cohorts between December 2017 and May 2018. Overall absence rates over the whole observation period and sub-rates over 14-days intervals were calculated; then comparison between the two groups were conducted applying Chi-square test.

Results: Influenza vaccination coverage among $4419 \mathrm{HCW}$ s was 14.5\%. Age, university degree, medical care area and physician profile were positively associated with vaccine uptake. Globally during influenza season non-vaccinated HCWs lost 2.47/100 person-days of work compared to 1.92/100 person-days of work among vaccinated HCWs ( $p<$ $0.001)$; significant differences in absences rates resulted when focusing on the influenza epidemic peak.

Conclusions: Factors predicting influenza uptake among HCWs were male sex, working within medical care area and being a physician. Absenteeism among HCWs resulted to be negatively correlated with vaccination against influenza. These findings add evidence to the urgent need to implement better influenza vaccination strategies towards HCWs to tackle vaccine hesitancy among professionals.
\end{abstract}

Keywords: Influenza, Vaccination, Coverage, Healthcare workers, Absences

\section{Background}

Influenza is an acute and highly contagious illness caused by type A and B influenza viruses, which leads every year in epidemics with increasing morbidity and mortality, particularly among high-risk groups [1]. The World Health Organization (WHO) estimates that annual epidemics are responsible for 3-5 million cases

\footnotetext{
* Correspondence: antinolfi.francesca@spes.uniud.it

'Department of Medicine, University of Udine, Udine, Italy

Full list of author information is available at the end of the article
}

of severe illness and between approximately 290,000 and 650,000 respiratory disease-related deaths worldwide [2]. Annual vaccination represents the most effective way to prevent influenza and is thus strongly recommended to those at high risk of complications, as well as to people who live with or care for people at high risk [1].

Studies estimate that during a mild influenza season $23 \%$ of healthcare workers (HCWs) get infected, although only $41-72 \%$ of them showing clinical symptoms; the remaining develop a subclinical, though still potentially

(c) The Author(s). 2020 Open Access This article is licensed under a Creative Commons Attribution 4.0 International License, which permits use, sharing, adaptation, distribution and reproduction in any medium or format, as long as you give appropriate credit to the original author(s) and the source, provide a link to the Creative Commons licence, and indicate if changes were made. The images or other third party material in this article are included in the article's Creative Commons licence, unless indicated otherwise in a credit line to the material. If material is not included in the article's Creative Commons licence and your intended use is not permitted by statutory regulation or exceeds the permitted use, you will need to obtain permission directly from the copyright holder. To view a copy of this licence, visit http://creativecommons.org/licenses/by/4.0/ The Creative Commons Public Domain Dedication waiver (http://creativecommons.org/publicdomain/zero/1.0/) applies to the data made available in this article, unless otherwise stated in a credit line to the data. 
transmissible, form of influenza [3]. The vaccination against influenza of this group of workers, along with protecting the single $\mathrm{HCW}$ from acquiring the disease, also enhance safety of patients who are at greater risk of severe complications, such as the elderly, individuals with diabetes or other chronic conditions [4-7]. In fact, the diffusion of influenza among HCWs could anticipate the spread of the disease among general population [8]. Once infected, an $\mathrm{HCW}$ may spread the virus to patients and colleagues resulting in an hospital outbreak, but to the community as well, finally increasing hospitalizations or even deaths, and therefore contributing to increase costs for the healthcare system $[4,5,9]$. For these reasons WHO, CDC (Centers for Disease Control and Prevention) and ECDC (European Centre For Disease Control and Prevention) strongly recommend annual vaccination against influenza for all HCWs $[1,10$, 11]. In Italy, the 2017-2019 National Vaccination Prevention Plan (PNPV) has identified HCWs as well as a target category for influenza vaccination as well, confirming its multiple aims toward patient and community's protection, but also in assuring the good functioning of health services during influenza season [12]. Despite strong recommendations to raise coverage among HCWs [1], compliance with influenza vaccination is still inadequate in many European countries [13] including Italy [13-17].

Another aspect to be considered is the possible economic impact of the HCWs' absence from work due to influenza, with possible healthcare services disruption and costs increase [18]. The point is: is there evidence that influenza vaccination is effective in preventing absenteeism due to illness?

The relationship between the two has been investigated by some Authors, but with no clear agreement. On one hand, Wilde et al. found that influenza vaccination did not reduce absenteeism among HCWs [19] and the study of Gianino et al. seems to confirm this evidence in the Italian context as well [20]. On the other hand, non-specific [21] and ILI-related [22] absenteeism among HCWs were significantly reduced by influenza vaccination; this evidence was confirmed by the recent Costantino et al. work which found a correlation between the increase in influenza vaccination coverage and the reduction of lost days of work [23].

The primary aim of this study is to evaluate the influenza vaccination coverage among HCWs of an Italian academic healthcare Trust during the 2017-2018 influenza season; the secondary aim is to identify predictive characteristics of vaccination adherence; finally, the third aim is to evaluate the effects of influenza vaccination on HCWs' absences from work.

\section{Methods}

During 2017, from November 6th to December 6th, the vaccination campaign against influenza was conducted within the Udine Healthcare and University Integrated Trust (Italy) throughout administration to HCWs of the quadrivalent split-virion influenza vaccine (Vaxigrip Tetra).

\section{Data collection}

Data about sex, age, educational level, professional profile, department, unit and (when the case) end of employment of HCWs working within Udine Healthcare and University Integrated Trust were collected. Using employee's anonymous identification number, data were linked to the 2017 influenza vaccination records. Two groups were identified: vaccinated and nonvaccinated HCWs. Professional profiles were coded as: physicians, nurses, midwifes, healthcare collaborators (including public health nurses, dietitians, physiotherapists, pediatric nurses, speech therapists, optometrists and psychologists) and auxiliary personnel. Departments and units were grouped by care area in medical, surgical, intensive, healthcare services, primary \& community, organization \& governance, and mixed. Medical residents, medical students, trainees and office workers were not included in the analyses. HCWs' data were merged with a database reporting $\mathrm{HCW}^{\prime}$ absences from work for any reason occurred between December 11th, 2017 (the first Monday following the start of the vaccination offer) and May 13th, 2018 (the last Sunday, 1 month after the end of the influenza season).

\section{Statistical analysis}

Categorical variables were reported as frequencies and percentages. Continuous variables were reported as mean \pm standard deviation (SD) or median with interquartile range, depending on data distribution. The Shapiro-Wilk test was used to study data distribution. For categorical variables, Chi-square or Fisher exact tests were conducted to detect significant differences between vaccinated and non-vaccinated group, as appropriate. The Student's t or the Mann-Whitney U tests were used to compare continuous variables between the two groups, as appropriate. Univariate and multivariate logistic regression were performed to identify the predictive variables for vaccination. All variables with $P$ value $<0.05$ were included in the multivariate regression model, according with backward stepwise selection method. To compare absences between vaccinated and non-vaccinated HCWs, absence rates were calculated by dividing the number of person-days lost due to absence, over the number of scheduled working person-days within the two groups. HCWs who have seen their 
employment contract terminated on a given date were dropped out from observation and were excluded from the denominator starting from that date. Overall rates were calculated over the whole observation period (from December 11th, 2017 to May 13th, 2018) and then subrates were calculated over 14-days time intervals. The comparisons between absence rates of the two groups were performed applying Chi-square test. The Bonferroni correction was applied when considering the comparisons over the 14-days time intervals (11 intervals). The adjusted type I error $\left(\alpha_{\mathrm{a}}\right)$ was fixed dividing the original type I error $\left(\alpha_{o}=0.05\right)$ by $11=0.005$. The 95\% (or $99.5 \%$ when Bonferroni was applied) confidence intervals for absence rates were calculated using the Wilson score method without continuity correction [24]. The confidence intervals for the differences between two rates were calculated applying the Newcombe-Wilson method without continuity correction [25]. Statistical significance for all the other tests was set accepting a type I error $\alpha<0.05$. All statistical analyses were performed using Stata/IC 13.0 (StataCorp LP, College Station, USA). The study was conducted in accordance with all national regulations, with the principles of the Declaration of Helsinki and it was approved by the Institutional Review Board of the University of Udine.

\section{Results}

\section{Influenza vaccination coverage}

According to administrative records, during the 2017 influenza vaccination campaign a total of $4419 \mathrm{HCWs}$ were employed at the Udine Healthcare and University Integrated Trust. The characteristics of the employees are summarized in Table 1 . During the vaccination campaign, 641 of them (14.5\%) were vaccinated for influenza. HCWs receiving the influenza shot were older (median age 50 years [range $\mathrm{Q}_{1}-\mathrm{Q}_{3}$ : 43-57]) than the others, whose median age was 46 years ([range $\mathrm{Q}_{1}-\mathrm{Q}_{3}$ : 38-53], $\left.p<0.001\right)$. Vaccination compliance was higher for males $(20.7 \%$ vs $12.6 \%$; $<<0.001)$, and for those having a university degree $(17.0 \%$; $<<0.001)$, compared with other employees having high school (13.2\%), primary or lower secondary education (12.2\%). Vaccination coverage rate resulted to be different also comparing professional profiles and care areas, as summarized in Table 1.

\section{Protective factors for vaccine uptake}

At the univariate logistic regression analysis, age and university degree were positively associated with influenza vaccination (respectively Crude OR $=1.037$ [95\%CI: 1.028-1.046], $p<0.001$ and Crude $\mathrm{OR}=1.463$ [95\%CI: 1.180-1.815], $p=0.001)$, while female sex resulted to be negatively associated (Crude OR $=0.552$ [95\%CI: 0.461-
0.662], $\mathrm{p}<0.001)$. There was no association with temporary/permanent nature of the employment (Crude $\mathrm{OR}=0.998$ [95\%CI: 0.676-1.475], $p=0.993$ ), nor with intra/extra-hospital healthcare service (Crude OR = 1.064 [95\%CI: 0.869-1.304], $p=0.546)$. At the same time, nurses (Crude OR $=0.340$ [95\%CI: 0.277-0.418], $p<0.001$ ), healthcare collaborators (Crude $\mathrm{OR}=0.404$ [95\%CI: 0.310-0.528], $\mathrm{p}<0.001$ ), auxiliary personnel (Crude OR $=0.256$ [95\%CI: 0.194-0.338], $\mathrm{p}<0.001$ ), and midwives (Crude OR $=0.103$ [95\%CI: 0.025-0.427], $p=$ 0.002 ) were less likely to be compliant to influenza vaccination than physician. When compared to medical care area, both surgical and organization \& governance care areas were negatively related to vaccination, respectively with Crude OR $=0.634$ ([95\%CI: $0.487-0.825]$, $p=0.001$ ) and Crude $\mathrm{OR}=0.650$ ([95\%CI: 0.506-0.835], $\mathrm{p}=0.001)$. On the contrary, healthcare services area was positively related to vaccination compliance when compared to medical area (Crude OR $=1.688$ [95\%CI: $1.226-2.325], \mathrm{p}=0.001)$. No differences were found for intensive care (Crude OR $=0.836$ [95\%CI: 0.602-1.160], $p=0.284$ ), primary \& community care (Crude $\mathrm{OR}=$ 0.799 [95\%CI: 0.611-1.045], $p=0.101$ ), nor mixed care (Crude OR $=0.735$ [95\%CI: $0.440-1.229], \quad p=0.241$ ) when compared to medical care area.

For the multivariate logistic regression analysis, all variables that were found to have a significant association with influenza shot at univariate analysis were included (sex, age, educational qualification, professional profile and care area). A negative association with influenza vaccination was confirmed for the following: female vs male sex, surgical vs medical area, all professional profiles (nurses, healthcare collaborators, auxiliary personnel and midwives) vs physicians. Crude and adjusted odds ratios and confidence intervals for each category are reported in Table 2. A positive association with influenza vaccination in the model was found for age, considered as a continuous variable (Adjusted $\mathrm{OR}=1.032$ [95\%CI: 1.023-1.042], $p<0.001)$.

\section{Absenteeism during influenza season}

At the first day of data collection about absences from work, there were a total of $4382 \mathrm{HCWs}$, as 37 employees of the initial population had dropped out from the cohort due to turn-over, new employment, retirement or other causes. At the end of the observation period there were $4280 \mathrm{HCWs}, 620$ of them having been vaccinated; the drop-out rate was not different between vaccinated and non-vaccinated groups. Globally, from December 11th, 2017 to May 13th, 2018, non-vaccinated HCWs lost 2.47 person-days / 100 person-days of work, compared to 1.92 person-days / 100 person-days of work among vaccinated HCWs $(p<0.001)$. Complete data are 
Table 1 Characteristics of the population of HCWs

\begin{tabular}{|c|c|c|c|}
\hline Characteristics & & $\begin{array}{l}\text { Vaccinated HCWs } \\
\text { n. (column \%) }\end{array}$ & $\begin{array}{l}\text { Total HCWs } \\
\text { n. (row \%) }\end{array}$ \\
\hline \multirow[t]{7}{*}{ Care area } & Healthcare services & $62(25.3)$ & $245(5.5)$ \\
\hline & Intensive & $51(14.4)$ & $355(8.0)$ \\
\hline & Medical & $237(16.7)$ & $1418(32.1)$ \\
\hline & Organization \& governance & $101(11.5)$ & $875(19.8)$ \\
\hline & Primary \& community & $85(13.8)$ & $615(13.9)$ \\
\hline & Surgical & $87(11.3)$ & $771(17.5)$ \\
\hline & Mixed & $18(12.9)$ & $140(3.2)$ \\
\hline \multirow[t]{3}{*}{ Educational qualification } & Primary or lower secondary education & $140(12.2)$ & $1143(25.9)$ \\
\hline & High school / Upper secondary education & $194(13.2)$ & $1466(33.2)$ \\
\hline & Bachelor's or equivalent level & $307(17.0)$ & $1810(41.0)$ \\
\hline \multirow[t]{2}{*}{ Employment } & Permanent & $610(14.5)$ & $4205(95.2)$ \\
\hline & Temporary & $31(14.5)$ & $214(4.8)$ \\
\hline \multirow[t]{2}{*}{ Healthcare service } & Extra-hospital & $139(13.9)$ & $999(22.6)$ \\
\hline & Intra-hospital & $502(14.7)$ & $3420(77.4)$ \\
\hline \multirow[t]{5}{*}{ Professional profile } & Auxiliary personnel & $81(9.2)$ & $878(19.9)$ \\
\hline & Healthcare collaborators & $95(13.8)$ & $687(15.6)$ \\
\hline & Midwives & $2(3.9)$ & $51(1.2)$ \\
\hline & Nurses & $240(11.9)$ & $2018(45.7)$ \\
\hline & Physicians & $223(28.4)$ & 785 (17.8) \\
\hline \multirow[t]{2}{*}{ Sex } & Female & $427(12.6)$ & 3386 (76.6) \\
\hline & Male & $214(20.7)$ & $1033(23.4)$ \\
\hline
\end{tabular}

summarized in Table 3. Considering 14 days-long intervals, the largest differences between non-vaccinated and vaccinated HCWs were found between January 08th and 21st $(\Delta=+1.20 \%$, 99.5\%CI: [0.70\% $-1.64 \%], p<0.001)$, January 22nd and February 04th $(\Delta=+1.52 \%$, 99.5\%CI: $[1.00 \%-1.97 \%], \mathrm{p}<0.001)$, and February 05th and 18th $(\Delta=+1.62 \%, 99.5 \% \mathrm{CI}:[1.15 \%-2.03 \%], \mathrm{p}<0.001)$. A visual representation of the absence rates of the two groups over time is shown in Fig. 1.

\section{Discussion}

During the 2017-18 vaccination campaign, the proportion of our HCWs getting their influenza shot was quite limited (14.5\%), despite being similar to what reported for the Italian [14, 26-30] and international context [31]. Low vaccine coverage among HCWs is well known and confidence, complacency and convenience factors have been reported to contribute to vaccine hesitancy [32]. In our case, uptake among nurses, auxiliary personnel and midwives are particularly alarming, considering on one hand the direct and prolonged contact these professionals have with high-risk patients, and on the other hand their missing role as vaccine promoters [33-35].
Professional profile is confirmed to be an important influenza vaccination predictor among HCWs $[14,15$, $17,27]$, as well as age $[15,17,28]$ and male $[17,28]$. Results seem to be still uncertain also concerning intensive care area as Esposito et al. [17] found HCWs working in emergency units to be more likely to undergo influenza vaccination when compared to HCWs working in medical department, but different aggregation of workers were made in the two studies making result not comparable. The detailed analysis on HCWs vaccination adherence allowed the hospital leadership to improve the influenza vaccination strategy, by focusing on less adherent HCWs categories: during 2018-19, targeted education was given to nurses and midwifes, and on-site vaccination days were set to tackle convenience-related issues of specific care areas.

During the observation period, absenteeism work in vaccinated HCWs resulted to be far lower than among non-vaccinated colleagues, either considering the whole observation period or focusing on the 2017-18 influenza epidemic peak [36], thus confirming the existing relation between HCWs influenza vaccination coverage and absenteeism [19, 21-23, 37-39]. Even if some colleagues suggest the existence of a ceiling effect when 
Table 2 Univariate and multivariate logistic regression model considering vaccination as dependent variable

\begin{tabular}{|c|c|c|c|c|c|}
\hline \multicolumn{2}{|l|}{ Characteristics } & \multirow{2}{*}{$\frac{\text { Crude OR }(95 \% \text { CI) }}{1.037(1.028-1.046)}$} & \multirow{2}{*}{$\begin{array}{l}\boldsymbol{p} \text {-value } \\
<0.001\end{array}$} & \multirow{2}{*}{$\frac{\text { Adjusted OR }{ }^{\mathrm{a}}(95 \% \mathrm{Cl})}{1.032(1.023-1.042)}$} & \multirow{2}{*}{$\frac{\boldsymbol{p} \text {-value }}{<0.001}$} \\
\hline Age (modeled as continu & & & & & \\
\hline \multirow[t]{7}{*}{ Care area } & Medical & 1 & - & 1 & - \\
\hline & Surgical & $0.634(0.487-0.825)$ & 0.001 & $0.662(0.514-0.853)$ & 0.001 \\
\hline & Intensive & $0.836(0.602-1.160)$ & 0.284 & & \\
\hline & Healthcare services & $1.688(1.226-2.325)$ & 0.001 & & \\
\hline & Primary \& community & $0.799(0.611-1.045)$ & 0.101 & & \\
\hline & Organization \& governance & $0.650(0.506-0.835)$ & 0.001 & & \\
\hline & Mixed & $0.735(0.440-1.229)$ & 0.241 & & \\
\hline \multirow[t]{3}{*}{ Educational qualification } & Primary or lower secondary education & 1 & - & & \\
\hline & High school / Upper secondary education & $1.093(0.866-1.379)$ & 0.455 & & \\
\hline & Bachelor's or equivalent level & $1.463(1.180-1.815)$ & 0.001 & & \\
\hline \multirow[t]{2}{*}{ Employment } & Permanent & 1 & - & & \\
\hline & Temporary & $0.998(0.676-1.475)$ & 0.993 & & \\
\hline \multirow[t]{2}{*}{ Healthcare service } & Extra-hospital & 1 & - & & \\
\hline & Intra-hospital & $1.064(0.869-1.304)$ & 0.546 & & \\
\hline \multirow[t]{5}{*}{ Professional profile } & Physicians & 1 & - & 1 & - \\
\hline & Healthcare collaborators & $0.404(0.310-0.528)$ & $<0.001$ & $0.424(0.321-0.560)$ & $<0.001$ \\
\hline & Nurses & $0.340(0.277-0.418)$ & $<0.001$ & $0.413(0.329-0.518)$ & $<0.001$ \\
\hline & Auxiliary personnel & $0.256(0.194-0.338)$ & $<0.001$ & $0.267(0.199-0.357)$ & $<0.001$ \\
\hline & Midwives & $0.103(0.025-0.427)$ & 0.002 & $0.168(0.040-0.705)$ & 0.015 \\
\hline \multirow[t]{2}{*}{ Sex } & Male & 1 & - & 1 & - \\
\hline & Female & $0.552(0.461-0.662)$ & $<0.001$ & 0.809 (0.660-0.993) & 0.043 \\
\hline
\end{tabular}

aThe non-associated variables were automatically excluded from the multivariate model by backward-stepwise selection method. All crude and adjusted ORs are shown

vaccine coverage is over 40\% [40], Italian and European results are still under this risk rate and therefore more efforts are needed to improve adherence. Such a detailed analysis of vaccination adherence should be performed each year by healthcare institutions to identify specific existing gaps in term of both magnitude and features to be tackled in the following influenza season. Moreover, the confirmation of both efficacy and effectiveness of influenza vaccination based on local data, could be important elements to include when presenting the influenza vaccination campaign to healthcare professionals to tackle vaccine hesitancy, as already suggested by Pereira et al. [38].

Vaccination against influenza can play a fundamental role in pursuing the reliability of healthcare services during influenza season [41] and is therefore an essential goal for healthcare organizations. As long as influenza vaccination is not mandatory for HCWs in Italy, the combination of factors predicting influenza uptake, vaccine hesitancy determinants and the most suitable interventions to put in place [42] should all be considered while planning strategies for the annual campaign against influenza within healthcare institutions.
This study has some limitations: firstly, the retrospective study design has intrinsic limitations. Secondly, we considered absences from work for any reason, without being able to distinguish clinical from other reasons underlying the absenteeism. Even if the provision of a medical certificate justifying absence is mandatory for employees, according to Italian law the employer cannot access those clinical contents. Nevertheless, we have no reason to believe that the distribution of absence causes was different between the two groups, therefore equally distributing this potential bias. Thirdly, we could not control for potential confounders about HCWs' health status or risky behaviors (e.g. smoking habits). Finally, the results presented in this study are based on data collected in 2018 for improvement purposes on HCWs vaccination campaign within the hospital. Since 2018 late summer when these analyses were presented to the leadership, several changes have been made to foster personnel compliance to the subsequent influenza vaccination campaigns held in 2019 and 2020. Despite these limitations, our study has strength points including the choice of observing all HCWs of our trust throughout the entire 2017-18 
Table 3 Comparison of the absence rate between vaccinated and not vaccinated HCWs in the considered period

\begin{tabular}{|c|c|c|c|c|c|c|c|c|}
\hline \multirow[t]{2}{*}{ Year } & \multirow[t]{2}{*}{ Period } & \multicolumn{2}{|l|}{ Non-vaccinated } & \multicolumn{2}{|l|}{ Vaccinated } & \multirow{2}{*}{$\begin{array}{l}\Delta \text { Absence } \\
\text { rate } \%\end{array}$} & \multirow{2}{*}{$\begin{array}{l}\text { Confidence } \\
\text { intervals }^{\mathrm{a}}\end{array}$} & \multirow[t]{2}{*}{$p$-value } \\
\hline & & $\begin{array}{l}\text { Absence person-days/Total } \\
\text { person-days }\end{array}$ & Rate $\%$ & $\begin{array}{l}\text { Absence person-days/Total } \\
\text { person-days }\end{array}$ & Rate $\%$ & & & \\
\hline 2017 & dec $11-\operatorname{dec} 24$ & $978 / 52,477$ & 1.86 & $132 / 8862$ & 1.49 & +0.37 & $-0.06-0.74$ & 0.015 \\
\hline $2017-2018$ & dec 25 - jan 07 & $899 / 52,308$ & 1.72 & $115 / 8842$ & 1.30 & +0.42 & $0.0001-0.76$ & 0.004 \\
\hline \multirow[t]{9}{*}{2018} & jan 08 - jan 21 & $1644 / 52,139$ & 3.15 & $172 / 8812$ & 1.95 & +1.20 & $0.70-1.64$ & $<0.001$ \\
\hline & jan 22 - feb 04 & $1855 / 52,040$ & 3.56 & 180/8784 & 2.05 & +1.52 & $1.00-1.97$ & $<0.001$ \\
\hline & feb 05 - feb 18 & $1689 / 51,928$ & 3.25 & $143 / 8764$ & 1.63 & +1.62 & $1.15-2.03$ & $<0.001$ \\
\hline & feb 19 - mar 04 & $1617 / 51,811$ & 3.12 & $226 / 8756$ & 2.58 & +0.54 & $-0.02-1.03$ & 0.007 \\
\hline & mar 05 - mar 18 & $1484 / 51,687$ & 2.87 & $234 / 8736$ & 2.68 & +0.19 & $-0.37-0.69$ & 0.317 \\
\hline & mar 19 - apr 01 & $1265 / 51,619$ & 2.45 & $213 / 8735$ & 2.44 & +0.01 & $-0.53-0.48$ & 0.944 \\
\hline & apr 02 - apr 15 & $956 / 51,510$ & 1.86 & $154 / 8722$ & 1.77 & +0.09 & $-0.38-0.49$ & 0.562 \\
\hline & apr 16 - apr 29 & $817 / 51,437$ & 1.59 & $148 / 8722$ & 1.70 & -0.11 & $-0.57-0.27$ & 0.456 \\
\hline & apr 30 - may 13 & $876 / 51,269$ & 1.71 & $139 / 8683$ & 1.60 & +0.11 & $-0.34-0.48$ & 0.471 \\
\hline Overall & & $14,080 / 570,225$ & 2.47 & $1856 / 96,418$ & 1.92 & +0.54 & $0.45-0.64$ & $<0.001$ \\
\hline
\end{tabular}

${ }^{a}$ The $99.5 \%$ C.I. was adopted when comparing absence rates along the 14 days-long periods to comply with the Bonferroni correction. The $95 \%$ C.I. was adopted when comparing absence rates of the overall period

† The differences in absence rates are considered statistically significant when $p<0.005$ according to the Bonferroni correction, except in the overall period comparison

influenza season. In addition, several variables were considered for the multivariate analysis to detect predictive HCWs characteristics for the influenza uptake and the great detail of uptake time trend allowed us to accurately analyze the relationship between vaccination against influenza and absenteeism.

\section{Conclusions}

Our results showed that factors predicting influenza uptake among healthcare workers were male sex, working within medical care area and being a physician. Absenteeism among healthcare workers resulted to be negatively correlated with vaccination against influenza. These findings add evidence to the urgent need to implement better influenza vaccination strategies towards healthcare workers to tackle vaccine hesitancy among professionals, as this target population can at the same time protect patients, preventing them to acquire influenza and also being a positive example for the community.

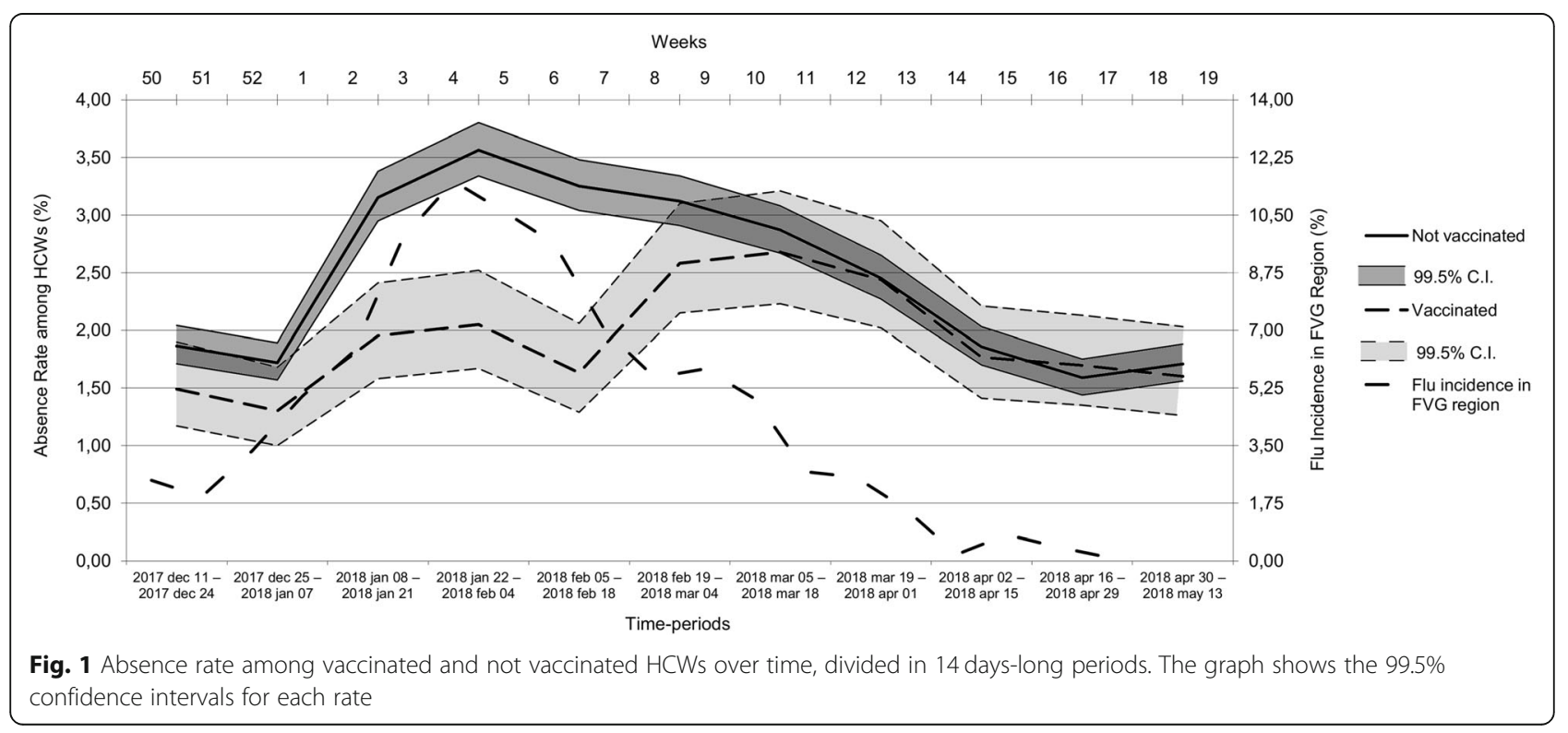




\section{Abbreviations}

HCWs: Healthcare workers; WHO: World Health Organization; CDC: Centers for Disease Control and Prevention; ECDC: European Centre for Disease Control and Prevention; PNPV: National Vaccination Prevention Plan; ILI: Influenza-like illness; SD: Standard deviation

\section{Acknowledgments}

None.

\section{Authors' contributions}

FA: conceptualization, investigation, data curation, writing-original draft. CB: investigation, data curation, formal analysis, writing-original draft. LB: conceptualization, methodology, writing-original draft. FM: conceptualization writing-original draft. FGB and DC: methodology, writing-review and editing. RC and SB: supervision, writing-review and editing. All authors critically reviewed the manuscript, provided significant editing of the article and approved the final manuscript.

\section{Funding}

No external funding was received for this study.

\section{Availability of data and materials}

The datasets used and/or analysed during the current study are available from the corresponding author on reasonable request.

\section{Ethics approval and consent to participate}

Ethical clearance to carry out the study was obtained from the Institutional Review Board, Department of Medicine, University of Udine, Italy.

\section{Consent for publication}

Not applicable.

\section{Competing interests}

The authors declare that they have no competing interests.

\section{Author details}

${ }^{1}$ Department of Medicine, University of Udine, Udine, Italy. ${ }^{2}$ ULSS4 Veneto Orientale Trust, San Donà di Piave, Venezia, Italy. ${ }^{3}$ Udine Healthcare and University Integrated Trust, Udine, Italy. ${ }^{4}$ Friuli Centrale Healthcare University Trust, Udine, Italy. ${ }^{5}$ Giuliano Isontina Healthcare University Trust, Trieste, Italy.

Received: 17 December 2019 Accepted: 27 July 2020

Published online: 18 August 2020

\section{References}

1. Vaccines against influenza WHO position paper - November 2012. Wkly Epidemiol Rec. 2012:87(47):461-76. http://www.who.int/wer.

2. Iulliano AM, Roguski KM, Chang HH, Muscatello DJ, Palekar R, Tempio S, et al. Estimates of global seasonal influenza-associated respiratory mortality: a modelling study. Lancet. 2018;391(10127):1285-300.

3. Elder AG, O'Donnell B, McCruden EA, Symington IS, Carman WF. Incidence and recall of influenza in a cohort of Glasgow healthcare workers during the 1993-4 epidemic: results of serum testing and questionnaire. BMJ. 1996; 313(7067):1241-2

4. Potter J, Stott DJ, Roberts MA, Elder AG, O'Donnell B, Knight PV, et al. Influenza vaccination of health care workers in long-term-care hospitals reduces the mortality of elderly patients. J Infect Dis. 1997 January; 175(1):1-6.

5. Carman WF, Elder AG, Wallace LA, McAulay K, Walker A, Murray GD, et al. Effects of influenza vaccination of health-care workers on mortality of elderly people in long-term care: a randomised controlled trial. Lancet. 2000 January 8;355(9198):93-7.

6. Ahmed F, Lindley MC, Allred N, Weinbaum CM, Grohskopf L. Effect of influenza vaccination of healthcare personnel on morbidity and mortality among patients: systematic review and grading of evidence. Clin Infect Dis. 2014 January;58(1):50-7.

7. Smith SA, Poland GA. Use of influenza and pneumococcal vaccines in people with diabetes. Diabetes Care. 2000;23(1):95-108.

8. Restivo V, Costantino C, Mammina C, Vitale F. Influenza like illness among medical residents anticipates influenza diffusion in general population: data from a national survey among Italian medical residents. PLoS One. 2016; 11(12):1-6.

9. Pagani L, Thomas Y, Huttner B, Sauvan V, Notaridis G, Kaiser L, et al. Transmission and effect of multiple clusters of seasonal influenza in a Swiss geriatric hospital. J Am Geriatr Soc. 2015 Apr;63(4):739-44.

10. Grohskopf LA, Sokolow LZ, Broder KR, Walter EB, Fry AM, Jernigan DB. Prevention and control of seasonal influenza with vaccines: recommendations of the advisory committee on immunization practices-United States, 2018-19 influenza season. Morbidity and Mortality Weekly Report. Centers for Disease Control and Prevention; 2018.

11. European Centre for Disease Prevention and Control. Seasonal influenza vaccination in Europe. Vaccination recommendations and coverage rates in EU Member States for eight influenza seasons: 2007-2008 to 2014-2015. Stockholm: ECDC; 2017.

12. Ministero della Salute. Piano Nazionale Prevenzione Vaccinale 2017-2019. 2017. Available from: www.salute.gov.it/imgs/C_17_pubblicazioni_2571_ allegato.pdf.

13. European Centre for Disease Prevention and Control. Seasonal influenza vaccination and antiviral use in EU/EEA Member States - Overview of vaccine recommendations for 2017-2018 and vaccination coverage rates for 2015-2016 and 2016-2017 influenza seasons. Stockholm: European Centre for Disease Prevention and Control; 2018.

14. Alicino C, ludici R, Barberis I, Paganino C, Cacciani R, Zacconi M, et al. Influenza vaccination among healthcare workers in Italy The experience of a large tertiary acute-care teaching hospital. Hum Vaccin Immunother. 2015; 11(1):95-100.

15. Fortunato F, Tafuri S, Cozza V, Martinelli D, Prato R. Low vaccination coverage among italian healthcare workers in 2013 - Contributing to the voluntary vs. mandatory vaccination debate. Hum Vaccin Immunother. 2015 11(1):133-9.

16. Blank PR, Schwenkglenks M, Szucs TD. Vaccination coverage rates in eleven European countries during two consecutive influenza seasons. J Infect. 2009;58:446-58

17. Esposito S, Bosis S, Pelucchi C, et al. Influenza vaccination among healthcare workers in a multidisciplinary University hospital in Italy. BMC Public Health. 2008:8:422. https://doi.org/10.1186/1471-2458-8-422.

18. Sartor C, Zandotti C, Romain F, Jacomo V, Simon S, Atlan-Gepner C, et al. Disruption of services in an internal medicine unit due to a nosocomial influenza outbreak. Infect Control Hosp Epidemiol. 2002 Oct;23(10):615-9.

19. Wilde JA, McMillan JA, Serwint H, Butta J, O'Riordan MA, Steinhoff MC. Effectiveness of influenza vaccine in health care professionals. JAMA. 1999; 281(10):908-13.

20. Gianino MM, Politano G, Scarmozzino A, Charrier L, Testa M, Giacomelli S, et al. Estimation of sickness absenteeism among Italian healthcare workers during seasonal influenza epidemics. PLoS ONE. 2017:12(8):e0182510. https://doi.org/10.1371/journal.pone.0182510.

21. Van Buynder PG, Konrad S, Kersteins F, Preston E, Brown PD, Keen D, et al. Healthcare worker influenza immunization vaccinate or mask policy: strategies for cost effective implementation and subsequent reductions in staff absenteeism due to illness. Vaccine. 2015;33(13):1625-8.

22. Imai C, Toizumi M, Hall L, Lambert S, Halton K, Merollini K. A systematic review and meta-analysis of the direct epidemiological and economic effects of seasonal influenza vaccination on healthcare workers. PLOS ONE. 2018;13(6):e0198685. https://doi.org/10.1371/journal.pone.0198685.

23. Costantino C, Casuccio A, Caracci F, Bono S, Calamusa G, Ventura G, et al. Impact of communicative and informative strategies on influenza vaccination adherence and absenteeism from work of health care professionals working at the university hospital of Palermo, Italy: a quasiexperimental field trial on twelve influenza seasons. Vaccines. 2020;8(1):1-12

24. Newcomb RG. Two-sided confidence intervals for the single proportion: comparison of seven methods. Stat Med. 1998;30(17):857-72.

25. Newcombe RG. Interval estimation for the difference between independent proportions: comparison of eleven methods. Stat Med. 1998;17:873-90.

26. Amodio E, Restivo V Firenze A Mammina C Tramuto F, Vitale F Can influenza vaccination coverage among healthcare workers influence the risk of nosocomial influenza-like illness in hospitalized patients? J Hosp Infect. 2014 Mar;86(3):182-7.

27. Bonaccorsi G, Santomauro F, Porchia BR, Niccolai G, Pellegrino E, Bonanni P, et al. Beliefs and opinions of health care workers and students regarding influenza and influenza vaccination in Tuscany, Central Italy. Vaccines (Basel). 2015;3(1):137-47. 
28. Amodio E, Di Pasquale M, Anastasi G, Gelsomino V, Morici M, Romano N et al. Influenza vaccination among healthcare workers and absenteeism from work due to influenza-like illness in a teaching hospital in Palermo. IJPH. 2010;7(3):311-8,

29. Genovese C, Picerno I, Trimarchi G, Cannavò G, Egitto G, Cosenza B, et al. Vaccination coverage in healthcare workers: a multicenter cross-sectional study in Italy. J Prev Med Hyg. 2019;60(1):E12-7.

30. Costantino C, Mazzucco W, Azzolini E, Baldini C, Bergomi M, Biafiore A, et al. Influenza vaccination coverage among medical residents an Italian multicenter survey. Hum Vaccin Immunother. 2014;10(5):1204-10.

31. European Centre for Disease Prevention and Control. Vaccine hesitancy among healthcare workers and their patients in Europe - A qualitative study. Technical report. Stockholm: European Centre for Disease Prevention and Control; 2015

32. World Health Organization. Report of the SAGE working group on vaccine hesitancy. Geneva: World Health Organization HQ; 2014. https://www.who. int/immunization/sage/meetings/2014/october/1_Report_WORKING_ GROUP_vaccine_hesitancy_final.pdf?ua=1. Accessed 30 July 2020.

33. Chung $\bar{Y}$, Schamel J, Fisher A, Frew PM. Influences on immunization decision-making among US parents of young children. Matern Child Health J. 2017 Dec;21(12):2178-87.

34. Smith PJ, Kennedy AM, Wooten K, Gust DA, Pickering LK. Association between health care providers' influence on parents who have concerns about vaccine safety and vaccination coverage. Pediatrics. 2006;118(5):1287-92.

35. Paterson P, Meurice F, Stanberry LR, Glismann S, Rosenthal SL, Larson HJ. Vaccine hesitancy and healthcare providers. Vaccine. 2016 Dec;34(52):6700-6.

36. Rizzo C, Bella A, Castrucci MR, Puzelli S, Paolotti D, de Martino A, et al. Rapporto della sorveglianza integrata dell'influenza. Stagione. 2017/2018. [Online]. [2019 May]. Available from: http://www.salute.gov.it/portale/ influenza/documenti/flunews/FluNews_2018_13.pdf.

37. Saxén H, Virtanen M. Randomized, placebo-controlled double blind study on the efficacy of influenza immunization on absenteeism of health care workers. Pediatr Infect Dis J. 1999 Sep;18(9):779-83.

38. Pereira M, Williams S, Restrick L, Cullinan P, Hopkinson NS. Healthcare worker influenza vaccination and sickness absence - an ecological study. Clin Med (Lond). 2017;17(6):484-9.

39. Chan SS. Does vaccinating ED health care workers against influenza reduce sickness absenteeism? Am J Emerg Med. 2007;25(7):808-11.

40. Dionne B, Brett M, Culbreath K, Mercier RC. Potential ceiling effect of healthcare worker influenza vaccination on the incidence of nosocomial influenza infection. Infect Control Hosp Epidemiol. 2016 July;37(7):840-4.

41. Costantino C, Restivo V, Tramuto F, Casuccio A, Vitale F. Influenza vaccination of healthcare workers in Italy: could mandatory vaccination be a solution to protect patients? Future Microbiol. 2019 Jun;14(9s):45-9.

42. European Centre for Disease Prevention and Control. Let's talk about hesitancy. Stockholm: European Centre for Disease Prevention and Control; 2016

\section{Publisher's Note}

Springer Nature remains neutral with regard to jurisdictional claims in published maps and institutional affiliations.

\section{Ready to submit your research? Choose BMC and benefit from:}

- fast, convenient online submission

- thorough peer review by experienced researchers in your field

- rapid publication on acceptance

- support for research data, including large and complex data types

- gold Open Access which fosters wider collaboration and increased citations

- maximum visibility for your research: over $100 \mathrm{M}$ website views per year

At BMC, research is always in progress.

Learn more biomedcentral.com/submissions 